\title{
PASADO, PRESENTE Y FUTURO DE LA NOCIÓN DE INFORMACIÓN
}

\author{
Rafael Capurro ${ }^{1}$ \\ Pesquisador e Membro do Institut für Digitale Ethik (Hochscule der Medien, Stuttgart).
}

\begin{abstract}
Resumo
Este artigo apresenta de forma resumida a complexa historia da noção de informação na tradução greco-romana, medieval e moderna. A partir da etimologia latina dessa noção e de suas raízes nos conceitos gregos de eidos / ideia e morphé se mostra como a noção de informação no seu conceito ontológico ('dar forma a algo') perde sua relevância na modernidade, mantendo-se o sentido de 'dizer algo a alguém'. As teorias da informação no século XX apoiadas na concepção de sistemas técnicos de transmissão de mensagens dão lugar a um renascimento da noção objetiva de informação, mas em um marco diferente a da filosofia clássica pré-moderna. Partindo da relação entre os conceitos de informação e de mensagem se apresentam possíveis caminhos para a noção de informação fundamentada em uma teoria de mensagens.
\end{abstract}

Palavras-chave: Informação. Conceito. História. Mensagem.

\section{PAST, PRESENT, AND FUTURE OF THE INFORMATION CONCEPT}

\begin{abstract}
This text provides an overview of the complex history of the notion of information in the Greek-Latin as well as in the Medieval and Modern traditions. It connects the Latin etymology of the term information with the Greek concepts of eidos/idea and morphé and shows how the objective meaning of information ('giving form to something') becomes obsolete in modernity where only the communicational meaning ('telling something to someone') Information theories in the $20^{\text {th }}$ Century are related to the development of technical systems of message transmission. They give rise to a renaissance of the objective notion of information but under a different framework as the one of classic pre-modern philosophy. Establishing a connection between the concepts of information and message several options are presented leading to a notion of information based on a theory of messages.
\end{abstract}

Keywords: Information. Concept. History. Message.

\section{Introdução ${ }^{2}$}

Investigar la historia de un concepto puede ser algo sumamente aburrido y de poca utilidad. Aburrido en tanto que dicha historia relate meros cambios semánticos más o menos accidentales como los que suelen encontrarse petrificados en las enciclopedias así como también cambios de significados en teorías científicas ya superadas o en especulaciones filosóficas de exclusivo interés histórico. Esto es aún más evidente si se trata de investigar la historia no de un concepto sino de palabras y de los significantes que las sostienen. En este caso aquella no trata de la aparente adecuación de un concepto a un fenómeno sino de la

\footnotetext{
${ }^{1}$ El texto fue presentado en el I Encuentro Internacional de Expertos en Teorías de Información, León (Espana) 2008, siendo accesible aquí <https://sites.google.com/site/proyectobitrum/recursos/documentos〉 así como también en mi sitio $<$ http://www.capurro.de/leon.pdf.>

${ }^{2}$ El autor agradece al Profesor Oscar Krütli (de la provincia argentina de Córdoba) y a José María Díaz Nafría por las muy valiosas revisiones críticas de ambos.
} 
historia singular de una palabra y sus derivados históricos en una o varias lenguas. Los cambios semánticos suelen ser aún más confusos y fortuitos que en el caso de nociones científicas o filosóficas. Los encontramos también petrificados en diccionarios etimológicos que sólo con mucha ingenuidad podría considerarse fuente del supuesto verdadero significado de un término, palabra o concepto, que es justamente el significado etimológico del término 'etimología', término que proviene del griego étymon que significa verdad en oposición a mentira. Homero cuenta, o mejor dicho canta, cómo Odiseo engaña a Penélope "contándole muchas historias semejantes a la verdad (étymoisin homoia)" (Od. 19, 203) sin descubrirle su verdadera identidad y sin contarle, por supuesto, las diversas aventuras eróticas con Circe, Calipso, las sirenas y Nausicaa, por recordar sólo algunos hitos amorosos de los diez años que duró su viaje de regreso.

¿Qué sentido positivo y productivo puede entonces tener investigar el pasado, presente y futuro de una noción y en especial, como en nuestro caso, de la noción de información? ${ }^{3}$ La respuesta a esta pregunta depende de lo que entendamos por lenguaje. La relación entre hombre, mundo y lenguaje ha sido uno de los grandes temas de la filosofía del siglo XX en lo que se suele llamar el giro lingüístico bajo la influencia de la lingüística y la semiótica tanto en la filosofía analítica como en diversas corrientes de la filosofía continental como es el caso de la fenomenología y la hermenéutica. Un lugar de encuentro de estas posiciones es la concepción del lenguaje no como un medio neutral y transparente a través del cual percibimos y concebimos la realidad tal cual es, sino como una condición de posibilidad ineludible del conocimiento y la acción humana. Esto quiere decir, siguiendo la tradición kantiana, que la realidad se articula como tal en el lenguaje y viceversa, el análisis del lenguaje nos muestra, siempre en forma parcial, quiénes somos y en qué mundo vivimos. Ludwig Wittgenstein tuvo gran influencia en el giro lingüístico con su concepción del significado como uso y el consecuente análisis de "formas de vida" y "juegos de lenguaje" a los que están siempre ligados dichos usos. ${ }^{4}$ Sin absolutizar el pragmatismo lingüístico de Wittgenstein podemos aún así rescatar su intuición de que tanto la reflexión sobre el mundo como sobre nuestras propias vidas no puede eludir al lenguaje siendo así posible un distanciamiento crítico de los significados contingentes aún en uso que nos permite no sólo crear nuevas formas de vida sino también nuevas teorías científicas, o sea, nuevas formas de comprender y responder a la realidad en la que vivimos así como aquella que somos y hacemos.

\footnotetext{
${ }^{3}$ El texto que sigue a continuación está basado en gran parte en el trabajo de Rafael Capurro y Birger Hjørland: The Concept of Information (2003). Ver también <http://www.capurro.de/infoconcept.html.>.Traducción, cambios y tesis adicionales van a cuenta de RC.

${ }^{4}$ Ludwig Wittgenstein: Philosophische Untersuchungen. (1984), § 43: "Die Bedeutung eines Wortes ist sein Gebrauch in der Sprache" ["El significado de una palabra es su uso en el lenguaje"]. Ver también $§ 23,138,156$.
} 
Visto así, investigar la historia tanto de una palabra como de un concepto, incluyendo significados y significantes, se transforma en una tarea semejante a la del geólogo o arqueólogo que intenta reconstruir un proceso natural y una forma de vida o una visión del mundo en base a restos a menudo aparentemente insignificantes depositados en épocas sucesivas en diversos sedimentos materiales o lingüísticos relacionados entre sí por corrientes a menudo subterráneas. La geología se vuelve genealogía. ${ }^{5}$ El análisis genealógico es especialmente interesante cuando tales términos, como en nuestro caso, se usan para caracterizar a una sociedad o incluso a toda una época. Es desde este punto de vista desde el que dicha investigación genealógica cobra importancia a la hora de dar razones plausibles de por qué dichos términos han adquirido tal relevancia y de cómo los podemos concebir en el futuro.

Vivimos, se ha dicho muchas veces, en la sociedad de la información o, aún más, en la época de la información en contraposición a la época industrial y a la agraria. Naturalmente que estas divisiones históricas son sumamente arbitrarias sobre todo si se las piensa en forma lineal siendo así que toda sociedad humana siempre ha estado basada en procesos informativos aunque no por cierto con la forma mediática actual de la información digital. El predominio de un factor determinado nos permite, con mayor o peor fortuna, utilizar adjetivos para calificar una época, oscureciendo a la vez otros aspectos no menos importantes. Todo concepto y todo término no está aislado sino que forma parte de una compleja red dinámica o histórica de relaciones con todos los estratos de la sociedad incluyendo cambios metafóricos y metonímicos de todo tipo tanto en los lenguajes llamados naturales como en los lenguajes artificiales incluyendo las teorías científicas y las especulaciones filosóficas, cambios que se pueden percibir en toda su complejidad especialmente en las grandes obras literarias. En el campo filosófico tales cambios son decisivos en tanto que se entienda por filosofía una reflexión metódica sobre las bases conceptuales del mundo y del ser humano. En este sentido el Diccionario histórico de la filosofía es un ejemplo de análisis histórico conceptual que implicó casi treinta años de investigación, no siendo esta, a mi modo de ver, ni aburrida ni mucho menos inútil. ${ }^{6}$

Si es así entonces que el mundo humano es el mundo de las cosas, las que encontramos y las que hacemos, que compartimos en y desde el lenguaje - incluyendo también lo que está más allá del mismo a lo que aluden, por ejemplo, la “cosa en si” kantiana y "lo real" de Lacan -, y si entendemos además la expresión "el mundo del lenguaje" en los

\footnotetext{
${ }^{5}$ Ver: On the Genealogy of Information. (1996). Disponível en: <http://www.capurro.de/cottinf.hbm>.

${ }^{6}$ Joachim Ritter et al. Historisches Wörterbuch der Philosophie. (1971-2007). 13 tomos. Ver aquí en especial el artículo de H. Schnelle: Information, p. 116-117.
} 
dos sentidos del genitivo subjetivo y objetivo, podemos plantearnos con más convicción la tarea de investigar el pasado, presente y futuro de la noción de información que es tal vez uno de los conceptos más difundidos y también más controvertidos de nuestro tiempo tanto en el ámbito de la vida social como en el de las teorías científicas particularmente desde mediados del siglo pasado. ${ }^{7}$

Mi curiosidad por este tema fue despertada hace unos treinta años por una conferencia del físico y filósofo alemán Carl Friedrich von Weizsäcker (1912-2007) titulada "Lenguaje como información" dada por primera vez en 1959 en la Academia de Bellas Artes de Munich. ${ }^{8}$ Weizsäcker (1974, p. 51) decía:

Hoy en día comenzamos a acostumbrarnos a concebir la información como una cosa diferente a la materia y la conciencia. Pero lo que hemos descubierto con esto es una vieja verdad en un lugar nuevo. Es el eidos platónico, la forma aristotélica, revestidas de tal manera que también un hombre del siglo XX pueda aprender a entrever su sentido. ${ }^{9}$

Weizsäcker alude implícitamente al famoso dicho de Norbert Wiener (1894-1964): "Información es información, no materia o energía. Ningún materialismo que no admita esto puede sobrevivir hoy."10 Es evidente que una historia crítica de esta noción es de tal complejidad y magnitud que no puede exponerse adecuadamente en un breve texto como el que sigue. Mi objetivo es indicar algunas pistas de trabajo que puedan llevar tanto a una revisión histórica de dicha noción como a posibles caminos futuros mientras nos encontramos confrontados con una sociedad que se autocaracteriza como "sociedad de la información”, y a la que, por cierto, añadimos como con mala conciencia: "y del conocimiento".

La brevedad de esta exposición me obliga también a simplificar extremadamente las historias que se han venido tejiendo tanto con la palabra, las palabras, como con el concepto, los conceptos, de información. Mi historia tiene una estructura relativamente simple. La noción de información en la antigüedad clásica y especialmente en el pensamiento de Platón y Aristóteles, si se la relaciona, como lo sugiere Weizsäcker, a los conceptos de idea/eidos y morphé, tiene un carácter objetivo y subjetivo - si me es permitido utilizar estas categorías propias de la modernidad - que se mantiene en la tradición latina clásica y medieval con el

\footnotetext{
${ }^{7}$ Para un análisis etimológico del concepto de información ver del autor: Information. Ein Beitrag zur etymolo-gischen und ideengeschichtlichen Begründung des In-formationsbegriffs. (1978) Disponível en: 〈http://www.capurro.de/info.html>.

${ }^{8}$ Carl Friedrich von Weizsäcker: Sprache als Information (1974).

9 "Man beginnt sich daher heute daran zu gewöhnen, daß Information als eine dritte, von Materie und Bewußtsein verschiedene Sache aufgefaßt werden muß. Was man aber damit entdeckt hat, ist an neuem Ort eine alte Wahrheit. Es ist das platonische Eidos, die aristotelische Form, so eingekleidet, daß auch ein Mensch des 20. Jahrhunderts etwas von ihnen ahnen lernt.” (WEIZSÄCKER, 1974, p. 51).

10 "Information is information, not matter or energy. No materialism which does not admit this can survive at the present day." (WIENER, 1961, p. 132).
} 
concepto de informatio. La modernidad rechaza la objetividad en el uso corriente concibiendo información como una categoría puramente subjetiva. En la actualidad, particularmente desde mediados del siglo pasado, tiene lugar un renacimiento del carácter objetivo en el contexto de las ciencias naturales y las tecnologías llamadas justamente de la información que repercute a su vez en el lenguaje ordinario.

Naturalmente que seguir la pista abierta por Weizsäcker significa tomar una decisión genealógica conectando la palabra y el concepto de información a su cotidiano uso subjetivo, o sea en el sentido de 'comunicar algo a alguien' con el fin de solucionar un problema en una situación determinada, y proyectar dicho concepto 2500 años atrás sin preguntarse normalmente qué otros términos podrían ser más adecuados que los de eidos o morphé correspondiendo al uso subjetivo actual como, por ejemplo, el complejo término lógos así como también la noción de mensaje (angelía). Estamos así enfrentándonos abiertamente a un problema de traducción cuya solución nunca es del todo adecuada porque todo término tiene en diferentes lenguajes y situaciones históricas: un contexto, un eco y una red semántica diferente. En otras palabras, nuestra historia está sumergida de partida en lo que la filosofía del siglo XX ha llamado el "círculo hermenéutico" (Hans-Georg Gadamer) o también "la indeterminación de la traducción" (W.V.O. Quine). Se trata de ver la identidad y la diferencia semánticas entre el pasado y el presente de un término, sus usos y relaciones, sin simplificaciones, o sea sin perder de vista posibles puntos de enlace que nos permitan no sólo conocer conjeturalmente el pasado desde la perspectiva presente sino también tomar distancia del presente observándonos desde el pasado, para así abrirnos a futuros cambios de sentido que serían, siguiendo a Wittgenstein, cambios de formas de vida. Es en este horizonte en el que nuestro tema creo que adquiere particular interés y relevancia.

\section{La noción de información en el pasado}

El filósofo británico John Austin (1911-1960), una delas figuras más importantes de la filosofía del lenguaje y creador de la teoría de los actos de habla ("speech acts"), escribe lo siguiente:

[Una] palabra nunca - bueno, casi nunca - se libera de su etimología y su formación. A pesar de todos los cambios en las extensiones y añadidosa sus significados y en realidad más bien penetrándolos y gobernándolos, persiste siempre la vieja idea [...]. Retrocediendo en la historia de una palabra, a menudo al latín, volvemos comunmente a imágenes o modelos de cómo las cosas suceden o son hechas. (AUSTIN, 1961, p. 149-15). ${ }^{11}$

\footnotetext{
11 "[A] word never — well, hardly ever — shakes off its etymology and its formation. In spite of all changes in the extensions
} 
La noción y el término 'información' provienen justamente del latín. El término informatio tiene como significados fundamentales el de la acción de dar forma a algo material así como el de comunicar conocimiento a una persona. Ambos sentidos, el ontológico y el epistemológico, están intimamente relacionados. ${ }^{12}$ El prefijo in tiene, en este caso, el sentido de acentuar la acción pudiendo significar también negación como en el caso de informis, es decir 'sin forma'. El término es utilizado por autores clásicos como Virgilio (70-19 AC) cuando se refiere, por ejemplo, en la "Eneida" a Vulcano y los cíclopes que modelan con sus manos un rayo para Zeus ("informatum manibus" Aen. 8, 426). Tertuliano (160-220 DC) llama a Moisés "populi informator" o sea un "modelador del pueblo", un uso pedagógico (y político) que se mantiene en algunas lenguas occidentales derivadas del latín muchos siglos más tarde.

Pero si queremos seguir la pista indicada por von Weizsäcker tenemos que preguntarnos si en algún texto de la filosofía latina clásica y medieval el término informatio tiene un uso técnico y una relación explícita a las nociones griegas tan cargadas de contenido filosófico como son idealeidos y morphé pero también a términos relacionados como es el caso de typos (impresión) o prólepsis (representación). La respuesta a esta pregunta es positiva en autores de la importancia de Cicerón (106-45 AC), Agustín (354-430 DC) y Tomás de Aquino (1225-1274 DC), por nombrar sólo a algunos de ellos. Cicerón traduce, por ejemplo, en De natura deorum el concepto epicúreo de prólepsis, o sea la representación de las imágenes de los dioses y las cosas en el alma humana, como "informatio rei" (nat. deor. 1, 43). En un contexto retórico Cicerón se propone describir plásticamente el ideal del orador ("informato" orat. 7) cuya actividad más eximia consiste en que pueda observar en su alma "lo que Platón llama ideas" (orat. 10). En otra obra Cicerón defiende a su maestro, el poeta griego Archias, nacido en Antioquía y acusado de haber adquirido ilegalmente la ciudadanía romana, indicando que él, Cicerón, fue instruído por Archias en técnicas como la escritura que tienen como finalidad la de educar o "in-formar" a los jóvenes en su devenir humano ("quibus aetas puerilis ad humanitatem informari solet") (Arch. 3).

Tanto en Agustín y como en Tomás de Aquino la influencia de la ontología y epistemología griegas en conexión con el término informatio son de gran importancia. En De

of and additions to its meanings, and indeed rather pervading and governing these, there will still persist the old idea. [...] Going back into the history of a word, very often intoLatin, we come back pretty commonly to pictures or models of how things happen or are done." (AUSTIN, 1961, p. 149-150).

${ }^{12}$ Los datos bibliográficos de las fuentes clásicas así como muchos otros textos a los que en parte aludo a continuación se encuentran en mi: Information (1978). 
trinitate Agustín llama al proceso de la percepción "informatio sensus" (trin. 11, 2, 3) y alude a las metáforas epistemológicas platónicas (Theat. 191d) y aristotélicas (De an. 424 a 17) de la "impresión" ("imprimitur") -Platón usa el término apotupousthai, Aristóteles los verbos dechetai y lambanei que significan recibir- de un anillo sello -“daktylios", en latín "digitus", de donde se deriva nuestro término "digital"- en la cera como imagen de la penetración, recepción y conservación de los objetos, o mejor dicho de sus representaciones o formas en la memoria. Haciendo referencia a lo que indicaré más adelante respecto a la relación entre información y mensaje, se podría interpretar este proceso no sólo como la impresión de una forma o estructura en un medio sino también como comunicación y recepción de una forma entendida ahora como mensaje. En De civitate dei Agustín describe al proceso de conocimiento o iluminación de la sociedad celeste como "informatio civitatis sanctae" (civ. $11,24)$.

En Tomás de Aquino el término informatio tiene un lugar central tanto en la epistemología como en la ontología. El hilomorfismo aristotélico es traducido informatio materiae pero interpretado dentro de la metafísica creacionista cristiana, que lleva a Tomás a diferenciar netamente entre el proceso físico y biológico de reproducción de formas "per modum informationis" - en especial la "información" del cuerpo por el alma - de la actividad divina "per modum creationis". ${ }^{13}$ En otras palabras, informatio y creatio expresan una diferencia ontológica fundamental ajena al pensamiento griego. El demiurgo platónico es un dios $\operatorname{artesano}^{14}$ que actúa, visto desde el pensamiento de Tomás, inmanentemente sólo "per informationem" mientras que el dios cristiano es una causa trascendente que crea "ex nihilo". Tomás hace así compatibles de forma elegante lo que hoy llamamos creacionismo y evolucionismo. En el plano epistemológico Tomás distingue entre "informatio sensus" e "informatio intellectus" siguiendo la doctrina aristotélica del 'retorno a los fenómenos' ("conversio ad phantasmata") (Summa theol. I, 14.2.co/4) y subrayando también el rol activo del "intellectus agens" en el proceso de re-conocimiento de las formas abstraídas de los fenómenos. Finalmente utiliza también el término informatio en un contexto pedagógico y ético (“informatio virtutum”, "informatio morum”) (Summa theol. III, 110.4.co/15).

Este amplio uso técnico de informatio es común, aunque no idéntico, a muchos autores medievales y es codificado tanto en las enciclopedias generales como en los diccionarios filosóficos a partir del siglo XVIII, a veces con una nota en la que se dice que el significado ontólogico ha caído en desuso en el lenguaje ordinario conservándose sólo como terminus

\footnotetext{
${ }^{13}$ Ver los textos en mi: Information (1978, p. 124-127).

${ }^{14}$ Sobre la cosmología platónica ver Serge Margel (1995).
} 
technicus en filosofía. ${ }^{15}$ Esta nota con todo su tono de diccionario aparentemente neutral, objetivo y escueto expresa en realidad nada menos que el cambio paradigmático de la concepción medieval del mundo enraizada en la filosofía greco-romana y en especial en el aristotelismo a la concepción subjetiva moderna de información con las teorías científicas y las formas de vida que se derivan de ella. El pasaje de la concepción de información como un proceso objetivo a la de un proceso subjetivo es vigente en lenguas europeas derivadas directamente del latín como el castellano, francés o italiano, o influenciadas por éste como el inglés, desde el siglo XIV. Tomemos a modo de ejemplo los significados del término información y sus derivados en el Diccionario de la lengua castellana llamado "de Autoridades" publicado en Madrid en 1734. ${ }^{16}$ Como se puede ver el significado ontológico de información no pertenece al lenguaje ordinario permaneciendo sólo la reminiscencia como término técnico de la filosofía escolástica. ¿Cuál es la causa de este desplazamiento de sentido en el lenguaje ordinario y como término técnico? La respuesta es casi obvia: se trata nada menos que de la transformación paulatina del sujeto sustancial medieval en el sujeto comunicacional moderno reforzado por el decaimiento progresivo de la filosofía escolástica a raíz del auge de la ciencia empírica moderna desde el siglo XVII, una tesis que habría que profundizar y matizar. ${ }^{17}$ Esta transición de la Edad Media a la Modernidad, ejemplificado en este caso por el pasaje o la pérdida en el lenguaje común del sentido objetivo de información ('dar la forma (sustancial) a algo') al sentido subjetivo moderno ('comunicar algo a alguien'), se puede ver claramente en la filosofía de René Descartes (1596-1650) quien llama ideas a las "formas del pensamiento" no como algo "pintado" (“depictae") en algún lugar del cerebro sino en tanto que "informan" ("informant") a la mente que se dirige a esta parte del cerebro. Descartes separa radicalmente, en oposición a la filosofía aristotélico escolástica, el proceso informativo (objetivo) sensible del cerebro, del conocimiento inmediato consciente de las ideas. ${ }^{18}$ En el Vocabulaire technique et critique de la philosophie indica André Lalande que en este texto se manifiesta claramente el pasaje del sentido escolástico de información de dar

\footnotetext{
${ }^{15}$ Ver por ejemplo Antoine Furetière: Dictionnaire universel contenant tous les mots françois tant vieux que modernes, \& les termes de toutes les sciences et des arts. (1725): "Informer, v. act. Servir de forme. Il ne se dit en ce sens qu'en phrase philosophique. L'âme informe le corps» así como citas de otras enciclopedias generales y filosóficas en mi: Information (1978, p. 155).

${ }^{16}$ Ver Anexo. Cf. del autor: Information (1978, p. 140).

17 "In the feverish demolition of medieval institutions in the seventeenth and eighteenth centuries, the notion that information consisted in the activity or process of endowing some material entity with form remained largely unchanged. But the notion that the universe was ordered by forms fell into disrepute, and the context of this informing shifted from matter to mind. Both changes inaugurated a massive inversion in the meaning of information." (PETERS, 1988, p. 12).

18 "Ideae nomine intelligo cujuslibet cogitationis formam illam, per cujus immediatam perceptionem ipsius ejusdem cogitationis conscius sum; adeo ut nihil possim verbis exprimere, intelligendo id quod dico, quin ex hoc ipso certum sit, in me esse ideam ejus quod verbis illis significatur. Atque ita non solas imagines in phantasia depictas ideas voco; imo ipsas nullo modo voco ideas, quatenis sunt in phantasia corporea, hoc est in parte aliqua cerebri depictae, sed tantum quatenus mentem ipsam in illam cerebri partem conversam informant." (DESCARTES, 1996, p. 160-161).
} 
una forma a una materia ("donner une forme à una matière") al uso (moderno) de dar a conocer algo a alguien (“faire connaître quelque chose à quelqu'un”). ${ }^{19}$ La duda metódica cartesiana tiene así un instrumento puramente racional (a priori, dirá luego Kant), que le permite juzgar clara y distintamente los engañosos datos empíricos.

La doctrina de las ideas de Descartes es central tanto para el empirismo como para el racionalismo modernos. ${ }^{20}$ La crítica al hilemorfismo y a la teoría aristotélica de la abstracción son temas clásicos de filósofos como Francis Bacon (1561-1625), John Locke (1632-1704), George Berkeley (1685-1753), David Hume (1711-1776) o Thomas Reid (1711-1796), pero en muchos casos dicho distanciamiento es aparente sobre todo en las teorías empiristas que usan el término "information(s)" así como "impression(s)". ${ }^{21}$ Visto así, el corte entre la escolástica y la modernidad se da menos con respecto a la noción de información misma que a su alcance o dominio específico, que para la modernidad es el conocimiento humano y no algo que subyace a todos los procesos naturales cósmicos. Este concepto excluye también connotaciones epistemológicas metafísicas o teológicas así como, en gran medida, las dimensiones pedagógicas y morales de la informatio medieval. Información tiene que ver con la actividad humana de percepción y conocimiento del mundo, no con los procesos formativos mundanos mismos o con el perfeccionamiento moral individual o social. El meollo del concepto epistemológico moderno de información es el acto humano de comunicar un conocimiento a alguien. El Diccionario de Autoridades lo dice en forma concisa: "INFORMAR. Vale también dar noticias à alguno ò ponerle en el hecho de alguna cosa. Lat. Informare. Certiorem facere" y lo atestigua por ejemplo con una cita de Miguel de Cervantes (1547-1616) quien describe en un famoso capítulo del Quijote, paladín de la libertad, cómo éste pide que le digan, es decir que le informen, por qué unos malhechores estaban encadenados:

Llegó, en esto, la cadena de los galeotes, y don Quijote, con muy corteses razones, pidió a los que iban en su guarda fuesen servidos de informalle $\mathbf{y}$

\footnotetext{
${ }^{19}$ André Lalande, volume 1, (1991, p. 514).

20 "The 'doctrine of ideas' developed initially by Descartes, was central to early modern philosophy, both rationalist and empiricist. Abandoning the 'direct perception' of the scholastics - the immediate communion of Intellect and Nature Descartes interposed 'ideas' between the two. An 'idea' was something present to the mind, an image, copy, or representation, with a problematic relation to real things in the world. For empiricists (like Locke), the stream of ideas was the raw material from which genuine knowledge could be built; for rationalists (like Descartes), it was a veil of illusion, to be pierced by logic and reason.” (PETERS, 1988, p. 13).

${ }^{21}$ J.D. Peters (1988, p. 12) afirma que Bacon en la "Great Instauration": "criticizes the logicians of his day for receiving 'as conclusive the immediate informations of the sense...' Instead, those 'informations' must be subjected, according to Bacon, to a sure plan that will sort the true form the false. Though Bacon's usage may not appear irreconcilable with our own, the inverted pluralization should tip us off that he does not completely share our prejudices (we should say "the information of the senses'). In fact, this locution exemplifies a perfectly hylomorphic notion of the workings of the senses: they are a kind of matter (wax being a favorite empiricist instance) on which objects of the world may leave their shapes or stamps. What is interesting here is that the site of information is being shifted from the world at large to the human mind and senses. This shift requires no break with scholastic notions of mind or nature."
} 
decille [mi subrayado, RC] la causa o causas por que llevan aquella gente de aquella manera.

Una de las guardas de a caballo respondió que eran galeotes, gente de su Majestad, que iba a galeras, y que no había más que decir, ni él tenía más que saber.

- Con todo eso -replicó don Quijote-, querría saber de cada uno de ellos en particular la causa de su desgracia. Añadió a éstas otras tales y tan comedidas razones para moverlos a que le dijesen lo que deseaba, que la otra guarda de a caballo le dijo:

- Aunque llevamos aquí el registro y la fe de las sentencias de cada uno destos malaventurados, no es tiempo éste de detenerles a sacarlas ni a leellas; vuestra merced llegue y se lo pregunte a ellos mesmos que ellos lo dirán si quisieren, que sí querrán, porque es gente que recibe gusto de hacer y decir bellaquerías.

Con esta licencia, que don Quijote se tomara aunque no se la dieran, se llegó a la cadena, y al primero le preguntó que por qué pecados iba de tan mala guisa. Él le respondió que por enamorado iba de aquella manera.

¿Por eso no más? -replicó don Quijote- . Pues si por enamorados echan a galeras, días ha que pudiera yo estar bogando en ellas.

- No son los amores como los que vuestra merced piensa -dijo el galeote- ; que los míos fueron que quise tanto a una canasta de colar, atestada de ropa blanca, que la abracé conmigo tan fuertemente, que a no quitármela la justicia por fuerza, aún hasta agora no la hubiera dejado de mi voluntad. ${ }^{22}$

Esta escena muestra claramente el uso moderno de la noción de información tanto en lo que se refiere al contexto epistemológico comunicacional como a su relación con la plausibilidad de los conocimientos trasmitidos basados en la comunicación oral así como en documentos escritos, especialmente oficiales que, dado el caso, pueden leerse públicamente. El concepto moderno de información está enraigado etimológicamente no sólo en términos como eidos/idea y morphe o forma sino también, en cuanto significa "decir algo a alquien", en el concepto de logos y con él en el nacimiento mismo de la filosofía. Retomaremos este asunto más adelante.

\section{La noción de información en el presente}

El concepto moderno subjetivo de información juega hoy día un rol preponderante en la así llamada sociedad de la información que emerge luego de la segunda guerra mundial conjuntamente con la disciplina científica correspondiente, la cual tiene raíces en la biblioteconomía, la informática y la ingeniería. La aplicación de la computación en los procesos bibliográficos da origen a una ciencia de la información que también es denominada documentación $\mathrm{y}$, particularmente en el contexto anglosajón, library and

\footnotetext{
${ }^{22}$ Miguel de Cervantes (2001, p. 218).
} 
information science (LIS). En el ámbito social la información es vista cada vez más como algo elemental para el funcionamiento de la sociedad junto al capital, el trabajo y las materias primas.

La partida de nacimiento de la ciencia de la información actual es sin lugar a dudas el artículo de Claude E. Shannon (1916-2001) "A Mathematical Theory of Communication" $(1948)^{23}$ en el que hace alusión al sentido semántico y pragmático usual de dicho concepto, es decir a la noción de información como el significado de un mensaje, como algo obvio y del que esta teoría (que concibe el problema fundamental de la comunicación como aquel de la reproducción de un mensaje en base a su codificación simbólica) se va a distanciar. ${ }^{24}$ Para Shannon no es información sino mensajes los que un emisor comunica a un receptor. El clasifica los sistemas de comunicación, es decir de trasmisión de mensajes, en tres categorías: discretos (la telegrafía), contínuos (radio y televisión) y mixtos. La definición de información de Shannon tiene que ver estrictamente con la posibles selecciones de mensajes o, más precisamente, de los signos disponibles para codificarlos. Así vista, esta teoría no es ni una teoría de la comunicación en el sentido de trasmisión de un significado, ni tampoco una teoría de la información en cuanto se entienda por este término el significado de un mensaje, sino que es una teoría de la codificación y trasmisión de mensajes. Como es sabido, Shannon establece una correlación entre información, es decir el número de selecciones posibles a fin de crear un mensaje, y la improbabilidad de dicha selección. Este concepto de información es, como lo indica, Warren Weaver (1894-1978), “desilusionante y extraño" (“disappointing and bizarre"). ${ }^{25}$ Es desilusionante para el uso moderno porque no tiene nada que ver con un significado vigente tanto en inglés como en otras lenguas europeas en, digamos, los últimos quinientos años. Y es extraño porque dos términos aparentemente opuestos, como son los de información e incertidumbre (o improbabilidad), son equiparados. Lo que trata de cuantificar Shannon no es un flujo informativo sino una trasmisión de mensajes que puede ser continua, discreta o mixta. ${ }^{26}$ Dicha trasmisión basada en un medio o, más precisamente, un mensajero,

\footnotetext{
${ }^{23}$ Claude E. Shannon (1948).

24 "The fundamental problem of communication is that of reproducing at one point either exactly or approximately a message selected at another point. Frequently the messages have meaning; that is they refer to or are correlated according to some system with certain physical or conceptual entities. These semantic aspects of communication are irrelevant to the engineering problem. The significant aspect is that the actual message is one selected from a set of possible messages." (SHANNON; WEAVER, 1972, p. 31)

${ }^{25}$ Shannon e Weaver (1972, p. 27).

26 "We may roughly classify communication systems into three main categories: discrete, continuous and mixed. By a discrete system we will mean one in which both the message and the signal are a sequence of discrete symbols. A typical case is telegraphy where the message is a sequence of letters and the signal a sequence of dots, dashes and spaces. A continuous system is one in which the message and signals are both treated as continuous functions, e.g., radio or television. A mixed system is one in which both discrete and continuous variables appear, e.g., PCM transmission of speech." (SHANNON; WEAVER, 1972, p. 34-35). PCM (Pulse-code modulation), o modulación por impulsos codificados (MIC), es la representación digital de una señal analógica.
} 
es vista como una relación formal entre mensajes. Al desligar los conceptos de información y de mensaje del contexto epistemológico humano antiguo y moderno, Shannon abre las perspectivas para un uso objetivo o formal de estos conceptos dejando explícitamente de lado los aspectos semánticos y pragmáticos que son característicos de los sistemas psíquicos y sociales en los que está basado el uso mo derno común de este término. Nos encontramos en el umbral de la cibernética de Norbert Wiener (1894-1964) y de sus ulteriores transformaciones que dan lugar a una prolongada discusión con matices muchas veces ideológicos o unilaterales de defensa de uno u otro sentido subjetivo u objetivo así como también de la búsqueda de una teoría unificada de la información. ${ }^{27}$ Este debate es un reflejo de la compleja historia tanto de este concepto como de la(s) palabra(s) (del signo/los signos) que lo sostiene y con las que está semánticamente ligado el concepto de mensaje.

Un ejemplo de este debate es el libro de Fritz Machlup y Una Mansfield "The Study of Information: Interdisciplinary Messages" en el que Machlup defiende la noción subjetiva de información en el sentido usual de contenido semántico de mensajes enviados y/o recibidos por la mente humana y critica el uso de este término en el contexto técnico. ${ }^{28}$ Es interesante ver cómo este debate se centra en el concepto de información al mismo tiempo que en ambos casos, o sea tanto Machlup como Shannon, utilizan el término mensaje, que es concebido técnicamente en la teoría de Shannon mientras que Machlup lo ubica sólo en el contexto de la comunicación humana.

Es importante recordar además que la noción técnica de información proviene ya desde fines del siglo XIX y comienzos del siglo XX de físicos e ingenieros como Ludwig Boltzmann (1844-1906), John von Neumann (1903-1957), Leo Szilard (1898-1964), Harry Nyquist (1889-1976) y Ralph V.L. Hartley (18881970) quien publica en 1928 un artículo con el título "Transmission of Information" en el cual escribe que dado que los sistemas de trasmisión eléctrica no tienen nada que ver con seres humanos sino con máquinas es mejor eliminar todos los "factores psicológicos" involucrados en dicha noción. ${ }^{29} \mathrm{El}$ debate filosófico en torno a la naturalización de la noción de información es decir a su ubicación más allá de la esfera humana tiene raíces tanto en las ciencias naturales como en la ingeniería y en particular

\footnotetext{
${ }^{27}$ A este debate alude por ejemplo Mario Pérez Gutiérrez (2000, p. 17-44).

28 "To telling something or to the something that is being told. Information is addressed to human minds and is received by human minds. [...] The requirement of truth or correctness should exclude false or incorrect messages; the requirement of value or usefulness should exclude messages not helpful in decisions and actions; the requirement of novelty should exclude repeated or redundant messages; the requirement of surprise should exclude messages that the recipient expected; the requirement of uncertainty-reduction should exclude messages that leave the recipient's state of uncertainty unchanged or increased; and so forth. No exhaustive enumeration of persuasive or dictatorial restrictions is here intended." (MACHLUP, 1983, p. 660).

29 "It is desirable therefore to eliminate the psychological factors involved and to establish a measure of information in terms of purely physical quantities." (HARTLEY, 1928, p. 536)
} 
en la informática. Cuando Norbert Wiener alude al concepto de información como a algo diferente a materia y energía cuestiona implícitamente al materialismo dialéctico. ${ }^{30}$

Pero en este uso objetivo actual hay varios cambios fundamentales con respecto a la filosofía clásica griega y latina especialemente en los siguientes puntos:

- El lugar celestial meta-histórico (topos noetós) de las ideas (platónicas) es ocupado ahora por la evolución mundanal.

- El lugar de la naturaleza (physis) lo ocupa ahora la mecánica cuántica.

- La noción (platónica) de participación (méthexis) es sustituída por la de comunicación.

- Los procesos informativos artificiales (poiesis) están basados en la tecnología digital.

Esta revitalización y reubicación del antiguo concepto objetivo de información en un marco moderno, es decir relacionado con las ciencias empíricas pero incluyendo la noción subjetiva - en particular la noción moderna de conciencia - se puede ver claramente, si bien no en toda su magnitud, en el pensamiento de Carl Friedrich von Weizsäcker para quien información es una categoría doble: ella significa (1) aquello que puede ser comprendido, así como también (2) aquello que genera información. ${ }^{31}$ Apoyándose en los conceptos griegos clásicos de eidos/idea y morphé Weizsäcker hace un puente, por así decirlo, no sólo con la tradición objetiva griega y medieval del concepto de información sino también con respecto a la dicotomía moderna que propone como irreconciliables una concepción objetiva y una subjetiva, es decir procesos informativos no humanos y humanos. Weizsäcker indica que para la filosofía griega el concepto de información, pensado desde su tradición etimológica y su historia conceptual, está relacionado con el de forma o estructura, es decir, con eidos/idea y morphé, lo cual desde el punto de vista del conocimiento humano equivale al concepto en caso de que se trate de una entidad lingüística con un significado unívoco. Esto, a su vez, sólo es posible en un marco abierto de posibilidades de sentido, el cual no es otra cosa que el lenguaje. Es por eso que Weizsäcker ve un círculo productivo o hermenéutico, como lo dirá la filosofía en el siglo XX, entre lenguaje e información. Dicho movimiento es, según Weizsäcker, pre-condición del pensamiento científico. Entre la plurivocidad del lenguaje natural y la univocidad de las nociones científicas hay una relación circular o, como decimos hoy, una recursividad que es característica del pensamiento humano puesto que se trata de

\footnotetext{
${ }^{30}$ Un ejemplo de concepción dialéctico-materialista de la noción de información es el libro de A.D. Ursul, Information: Eine philosophische Studie. (1970). La idea de Wiener es desarrollada por Gotthard Günther (1963).

31 “1. Information ist nur, was verstanden wird. [... 2. Information ist nur, was Information erzeugt.” (WEIZSÄCKER, 1974, p. 351-352).
} 
observadores limitados o finitos por estar ubicados dentro del lenguaje y dentro de la evolución. ${ }^{32}$ Pero Weizsäcker indica también que las estructuras biológicas o, en términos más generales, la evolución misma, pueden ser concebidas como "un crecimiento de formas medido como un crecimiento de información". ${ }^{33}$ Dichas formas pueden considerarse como potencialmente cognoscibles, con lo cual pasamos de la segunda a la primera noción de información. Además un organismo puede entenderse en su totalidad como producto de la información genética. Weizsäcker llama a estas formas generativas "semántica objetivada" (“objektivierte Semantik"). ${ }^{34} \mathrm{Al}$ nivel de la termodinámica la información actual significa lo contrario de entropía mientras que a nivel de la conciencia la información tiene dimensiones sintácticas, semánticas y pragmáticas. Weizsäcker traduce, en otras palabras, el concepto técnico de información entendido como 'trasmisión de señales' en el contexto de la termodinámica y la evolución biológica. La entropía termodinámica mide la distancia entre el conocimiento a nivel macro y microscópico. La probabilidad de acontecimientos posibles tiene lugar dentro de condiciones específicas. Esto significa también que no existe un concepto absoluto de información. Además implica que las formas o estructuras tanto objetivas como subjetivas ya no se conciben como algo permanente o absoluto, sino como mutables en el tiempo. ${ }^{35}$ Basado en la dualidad de la noción de información, Holger Lyre desarrolla una teoría cuántica de la información con alternativas básicas que representan el contenido de la información como un decisión si/no, o sea como un bit cuanto-teórico de información potencial (“Ur"). ${ }^{36}$

Esta idea de unidades de información es a primera vista semejante a la teoría objetiva de la información desarollada por Tom Stonier (1927-1999) para quien la información, o más exactamente los "infons", existen independientemente del pensamiento humano, como componentes intrínsecos del universo. ${ }^{37}$ Pero justamente aquí radica la diferencia con el pensamiento de corte kantiano de Weizsäcker y Lyre para quienes los "Urs" no son partículas espacio-temporales. Stonier distingue claramente entre información y sentido (“meaning”). El concepto subyacente es el de mensaje. De acuerdo a Stonier la información consiste, por ejemplo, en las letras del alfabeto o los nucleótidos de un fragmento de ADN. El mensaje o, mejor dicho, la información trasmitida por un mensaje, adquiere sentido sólo cuando es

\footnotetext{
${ }^{32}$ Weizsäcker (1974, p. 351).

${ }^{33}$ Carl Friedrich von Weizsäcker: Zeit und Wissen. (1992).

34 "So ist also Evolution ein Anwachsen der Menge an Form, gemessen als ein Anwachsen der Information." (WEIZSÄCKER, 1973, p. 24).

35 Weizsäcker (1973).

${ }^{36}$ Holger Lyre (1998). De acuerdo a Charles H. Bennett y David P. DiVicenzo (2000), una teoría de la información basada en principios cuánticos que complementa a la teoría clásica de Shannon y ofrece beneficios para la criptografía y el proceso cuántico de información. Un bit cuántico o "qubit" es un sistema cuántico que sólo presenta dos posibles estados.

37 Tom Stonier (1997).
} 
procesada por un receptor. ${ }^{38}$ Desde principios de la década de 1990 el grupo "Foundations of Information Science", coordinado por Pedro Marijuán, discute activamente sobre la noción de información siguiendo los caminos abiertos por Stonier y otros científicos. ${ }^{39}$ Se busca una teoría unificada de la información que incluya los aspectos subjetivos modernos así como los aspectos objetivos subyacentes en la tradición premoderna de este concepto y que renacen en la actualidad. ${ }^{40}$ Algunos filósofos han atacado vivamente la aplicación de la noción de información en las ciencias naturales entendiéndola como una falsa analogía o como un concepto redundante con respecto al de causalidad. ${ }^{41}$ Peter Fleissner y Wolfgang Hofkirchner han llamado a esta discusión "el trilema de Capurro", que es en realidad un trilema aristotélico, indicando las siguientes opciones:

1) Univocidad: el concepto de información significa lo mismo en todos los ámbitos. Desventaja: reduccionismo.

2) Analogía: el concepto de información tiene su sentido originario en un ámbito, por ejemplo el de la comunicación humana, y se lo aplica sólo analógicamente a otros niveles. Desventaja: antropomorfismos

3) Equivocidad: el concepto de información tiene significados diferentes en diversos ámbitos. Desventaja: síndrome de Babel, los discursos y teorías científicas se encapsulan mutuamente. $^{42}$

Esto nos lleva a presentar en forma sumaria la discusión de la noción de información en humanidades y ciencias sociales. ${ }^{43} \mathrm{El}$ debate se concentra particularmente en el síndrome reduccionista es decir el temor a reducir al ser humano a un mero organismo o máquina procesadora de información perdiendo de vista los complejos componentes culturales que caracterizan al conocimiento $\mathrm{y}$, mas exactamene, al observador humano. Si, como dijo Gregory Bateson (1904-1980), información es "una diferencia que hace una diferencia"44 la pregunta es entonces cual es la diferencia que "hace" un observador humano. Un aspecto importante de este "hacer" es el de seleccionar. Información es el proceso y el producto de un proceso de selección. Este aspecto juega un rol decisivo en la teoría de la información de Shannon la cual excluye, como ya vimos, los aspectos semánticos y pragmáticos de dicha

\footnotetext{
38 Tom Stonier (1996).

39 Pedro Marijuán (1996, p. 87-96). Ver el sitio <http://fis.icts.sbg.ac.at/>. Para una visión detallada de la nociones de información particularmente en las ciencias naturales ver Horst Völz (1982) e (1983).

${ }^{40}$ Rafael Capurro, Peter Fleissner e Wolfgang Hofkirchner (1999, p. 9-30). Versión online:

<http://www.capurro.de/trialog.htm.>

41 Peter Janich (1998, p. 169-182). Ver mi crítica: “Das Capurrosche Trilemma” (1998, p. 188-189) y la discusión subsiguiente en mi: Informationsbegriffe und ihre Bedeutungsnetze. (2001, p. 14-17).

${ }^{42}$ Peter Fleissner y Wolfgang Hofkirchner (1995, p. 126-131).

${ }^{43}$ Para una visión de conjunto ver Lars Qvortrup (1993, p. 3-24).

${ }^{44}$ Gregory Bateson (1972, p. 459): "a difference that makes a difference".
} 
selección adjudicándolos al trasmisor y receptor humanos y retomando así el sentido moderno y actual de la noción de información en el lenguaje ordinario. Pero es claro también que ambos procesos de selección, el humano y el no-humano, son idénticos en lo que respecta a la selección pero difieren en el tipo de interpretación así como que juegan causas (más o menos determinísticas) y motivos (en el caso de interpretación humana). Es por eso que Bar-Hillel (1915-1975) llamó la atención a las "ambigüedades y trampas semánticas" en la teoría de la información de Shannon que él prefiere llamar "teoría de trasmisión de señales" proponiendo, junto con Carnap (1891-1970), una teoría semántica de la información ubicada en un ámbito lingüístico. ${ }^{45}$ Un camino semejante pero no idéntico es el de la teoría de la información semántica de Dretske quien distingue entre información y significado (“meaning”): "información es lo que es capaz de producir conocimiento" siendo este último relativo a un pre-conocimiento. ${ }^{46}$ La noción de información queda así íntimamente ligada a la de conocimiento humano o, en forma más general, a sistemas cognitivos: "conocimiento es una creencia producida por la información". ${ }^{47}$ Sistemas cognitivos creadores de sentido se diferencian así de meros sistemas de procesamiento de información como son las computadoras que sólo son capaces de manipular símbolos. Este límite congnitivista fue criticado más tarde por autores como Barwise, Perry, Israel y Seligman quienes desarrollan una teoría semántica basada en la idea de regularidad entre diferentes tipos de situaciones y desde la cual la teoría de Dretske es vista como un caso particular. Información no se refiere entonces a una propiedad de algo sino que depende del contexto. ${ }^{48}$ Pérez Gutiérrez desarrolló posteriormente esta teoría desligando el concepto de información de toda referencia a la interpretación por parte del receptor, sin hacer del objeto de este concepto algo absoluto, sino todo lo contrario, mostrando cómo la noción de información se refiere a algo situacional y contingente con marcos de referencias específicos. ${ }^{49}$

En la tradición de la teoría de sistemas, Oeser indica que la objetividad del conocimiento científico no se basa en la eliminación del sujeto cognoscente sino en un proceso intersubjetivo informacional. ${ }^{50}$ Información tiene siempre un sistema como marco de referencia, a lo cual aluden otros autores que se basan en la cibernética de segundo orden de

\footnotetext{
${ }^{45}$ Yehoshua Bar-Hillel (1973, p. 296): "Even more important than the change of name from Information Theory to Theory of Signal Transmission (plus, perhaps, Theory of Coding) would be to discard the use of the term 'information' within this theory, with all its ambiguities and semantic traps". Ver también con anterioridad: Yehoshua Bar-Hillel y Rudolf Carnap (1953, p. 147-157).

${ }^{46}$ Fred I. Dretske (1981).

47"knowledge is information-produced belief." (DRETSKE, 1981, p. 91-92).

48 Jon Barwise y John Perry (1983); Jon Barwise y Jerry Seligman (1997); David Israel y John Perry (1990, p. 1-19.)

${ }^{49}$ Mario Pérez Gutiérrez (2000).

${ }^{50}$ Erhard Oeser (1976).
} 
Humberto Maturana y Francisco Varela (1946-2001) así como en la semiótica. ${ }^{51}$ Para cibernéticos como Heinz von Foerster (1911-2002), información es una diferencia mental en el observador el cual construye o descubre una diferencia en el mundo exterior. ${ }^{52}$ El sociólogo Niklas Luhman ha desarrollado ampliamente una teoría de sistemas psíquicos y sociales en los que la construcción de sentido se basa en un proceso de comunicación cuyos tres elementos son: una oferta de sentido (“Mitteilung"), un proceso de selección llamado “información" ("Information"), y la integración de lo seleccionado en el sistema, a lo que Luhmann llama "comprender" ("Verstehen"). ${ }^{53}$ Esta teoría cuestiona la metáfora que representa a la información como algo que es trasmitido por un emisor a un receptor. Ya que el emisor hace una selección como bien lo veía Shannon. Otro autores como Kornwachs proponen una definición pragmática de información. ${ }^{54}$

Información es hoy un concepto clave en sociología, ciencia política y economía. A modo de ejemplo baste recordar las investigaciones de Manuel Castells. ${ }^{55}$ De acuerdo a Bougnoux, los conceptos de información y comunicación están relacionados inversamente: comunicación se refiere a previsión y redundancia mientras que información tiene que ver con lo nuevo e imprevisto. No existe una "información en si" sino que siempre hay algún tipo de redundancia o "ruido". Informar a otros o informarse a sí mismo significa para Bougnoux seleccionar y evaluar. Esto es particularmente relevante en el campo del periodismo y los medios masivos así como también en Internet. ${ }^{56}$ Para Alfons Cornella, las empresas son información. ${ }^{57}$ La noción de información juega un rol importante en las teorías de la gerencia del conocimiento. Para Nonaka y Takeuchi información es el conocimiento potencial exteriorizado y gerenciable, mientras que conocimiento es un proceso que tiene lugar en el sujeto cognoscente. ${ }^{58}$ Estas teorías están relacionadas con la larga historia de la noción de información en el campo de la biblioteconomía y de la documentación que, como indicaba al comienzo, llevó a la denominación "library and information science". 59

Resumiendo esta discusión de la noción de información que ha tenido lugar particularmente en la segunda mitad del siglo XX podemos constatar un creciente interés por la perspectiva objetiva ya presente en la tradición clásica si bien ahora, como ya lo hacíamos

\footnotetext{
${ }^{51}$ Humberto R. Maturana y Francisco J. Varela (1980); Søren Brier (1999, p. 79-99). Ver también Lars Qvortrup (1993).

${ }^{52}$ Heinz von Foerster (1984).

${ }^{53}$ Niklas Luhmann (1987, p. 193-194).

${ }_{55}^{54}$ Klaus Kornwachs (1996, p. 163-185).

${ }_{55}^{55}$ Manuel Castells (1996). Ver también Frank Webster (1995).

${ }^{56}$ Daniel Bougnoux (1993).

${ }^{57}$ Alfons Cornella (2000).

${ }^{58}$ Ver por ejemplo: Ikujiro Nonaka y Hirotaka Takeuchi (1995).

${ }^{59}$ Para un análisis detallado de las teorías de la información en este campo ver Rafael Capurro y Birger Hjørland (2003, p. 377-396).
} 
explícito, dentro del horizonte de la ciencia empírica y la tecnología de la computación. Hay una tendencia, cuestionada por varios autores, a relativizar e incluso a eliminar el aspecto subjetivo. Es claro que, al menos, quinientos años de un uso exclusivamente subjetivo en el lenguaje ordinario no pueden ignorarse u olvidarse fácilmente, aun cuando las ciencias a menudo definen sus términos independientemente de su uso diario sin que esto cause, como en este caso, una controversia no sólo de carácter científico sino también social y ético. Esto se debe, a mi paracer, a que la noción objetiva de información es retroproyectada a la autoconstitución del sujeto que se ve así aparentemente privado de $\operatorname{su(s)}$ diferencia(s) o incluso equiparado a otros sistemas no humanos. Pero en realidad, la noción de información se refiere en muchas de las significaciones científicas analizadas a resortes o "mecanismos de selección" ("release mechanisms") como los llama Karpatschof, ${ }^{60}$ lo que en principio puede concebirse y aplicarse específicamente en diversos niveles, sin caer necesariamente en reduccionismos. Para que esto no suceda es indispensable un estudio genealógico de este y otros conceptos. La tendencia a vernos como objetos está siempre latente pero ella es especialmente virulenta en el momento en que el conocimiento científico objetivante de la realidad y su instrumentalización técnica deviene un horizonte englobante de la modernidad.

\section{La noción de información en el futuro}

En el marco de una naciente filosofía de la información, que todavía toma poca conciencia del complejo pasado de esta noción y de la(s) palabra(s) que la sostiene(n), Floridi define información, por un lado desde la perspectiva de la teoría de Shannon y de la teoría semántica, ${ }^{61}$ pero retoma también, por otro lado, la tradición clásica del concepto de forma, ubicándolo dentro de lo que yo llamo una teoría, si bien todavia no una filosofía, del mensaje. ${ }^{62}$ Los "objetos informacionales" de Floridi son algo así como las mónadas de Leibniz o las ideas platónicas, es decir tienen un status ontológico esencialmente positivo y universal aunque al mismo tiempo, si se los considera, como lo hace Floridi, como mensajes, pueden ser de mayor o menor valor (moral).

Siguiendo este camino, iniciado ya por Weizsäcker, quisiera darle un giro al paradigma ontológico o, mejor dicho, metafísico informacional propuesto por Floridi y en vez de basar la noción de mensaje en la de forma o "objetos informacionales" transformando a

\footnotetext{
${ }^{60}$ Benny Karpatschof (2000).

${ }^{61}$ Luciano Floridi (2004) e Luciano Floridi (2004, p. 40-61).

${ }^{62}$ Luciano Floridi. (2003, p. 287-304); Luciano Floridi (1999, p. 37-56). Ver del autor: Angeletics (2003, p. 105-122).
} 
estos en un supuesto metafísico, ${ }^{63}$ pensar dicha relación al revés: lo primario es el darse de dichos objetos -y el darse mismo de ese darse-; y dicho 'darse' se manifiesta como tal a un sujeto finito para quien su propio ser es algo dado como un poder-ser al que él mismo es capaz de responder. ${ }^{64}$ Quidquid recipitur ad modum recipientis recipitur dice ya el clásico axioma medieval. ${ }^{65}$ El ser del ser humano es responsabilidad también en el sentido de su capacidad de seleccionar y responder a mensajes u "ofertas de sentido" ("Mitteilung") como lo concibe Luhmann. ${ }^{66}$ El concepto de donación es, a diferencia del de creación, fenomenológico y no metafísico. El mundo o, más en general: el ser (pensado verbalmente), se da. Lo que es, se da como forma en el caso de procesos naturales o, como "oferta de sentido" en el caso de sistemas psíquicos y sociales. Información es, en ambos casos, un "resorte" de selección.

Visto así, el concepto moderno de in-formación está enraizado etimológicamente no sólo en términos como eidos/idea y morphe o forma sino también, en cuanto significa "decir algo a alquien", es decir, en el concepto de $\log o s$ y con él en el nacimiento mismo de la filosofía. ¿En qué sentido? En cuanto que el Sócrates platónico sustituye el esquema heteronómico subyacente al concepto de mensaje por un método basado en el decirse y darse razones (logon didonai) mu-tuamente en vez de dejarse decir sim-plemente algo por el otro, particularmente si ese otro ocupa un lugar de poder del que aparentemente emana un saber y un mandar no cuestionables. ${ }^{67}$ En otras palabras, lo que Sócrates introduce es nada menos que el principio de recursividad como método de búsqueda de la verdad. La polémica se dirige hacia un concepto, el de mensaje (angelía), que se usaba especialmente aunque no exclusivamente en contextos de poder políticos y/o militares así como también en contextos míticos o poéticos particularmente en relación a la actividad del poeta como mediador entre lo divino y lo humano así como por la figura de Hermes (pero también de Iris) el mensajero de los dioses. ${ }^{68}$ Pero la polémica socrática propaga un intercambio aparentemente horizontal de mensajes manteniendo al mismo tiempo el derecho de autonomía de los participantes de este diálogo. Con esto entra de nuevo, si bien implícitamente, el concepto de mensaje en el juego dialéctico con una importante transformación, la de ser reversible: el receptor de un mensaje

\footnotetext{
${ }^{63}$ Ver mi crítica a la metafísica informacional de Floridi en mi: Towards an ontological foundation of information ethics. (2006, p. 175-186).

${ }^{64}$ Estoy haciendo referencia a la concepción heideggeriana de la existencia y a su crítica a la metafísica desde una ontología donde el concepto de ser es indeterminado o vacío. Ver Martin Heidegger (1976) y mi: Towards an ontological foundation of information ethics (2006).

${ }^{65}$ Ver por ejemplo Tomás de Aquino (1923), Summa Theologica, I q.12 a.4 c.: "Cognitum autem est in cognoscente secundum modum cognoscentis."

${ }^{66}$ Niklas Luhmann (1987).

${ }^{67}$ Para un desarrollo más extenso de esta tesis ver del autor: Leben im Informationszeitalter (1995, p. 97-109); y Ethik im Netz (2003, p. 105-122)

${ }^{68}$ Sobre el contexto semántico del concepto de angelía ver del autor: Information (1978, p. 46-49).
} 
puede transformarse en emisor.

El principio de recursividad es fundamental para el concepto actual de información en el marco de la cibernética. No es por casualidad que el concepto de mensaje no menos que el de medio están en el centro de la teoría de comunicación de Shannon y de sus posteriores transformaciones. Quien dice mensaje está implicando siempre un medio o mensajero. La diferencia mensaje/mensajero es fundamental. Ella nos distingue de la metafísica platónica en tanto que esta concibe las ideas como mensajes puros o metalingüísticos, ubicados en un lugar más allá de lo simbólico o del mundo mediatizado por el lenguaje (topos noetos). Tanto un mensaje sin mensajero como un mensajero sin mensaje son, con otras palabras, conceptos límites. No sólo la teoría de la información sino también la teoría de los medios, tan discutida en la segunda mitad del siglo pasado, pueden encontrar su fundamento en una teoría de mensajes o angelética. ${ }^{69}$ Dicha teoría es aún incipiente mientras que las sociedades de mensajes evolucionan tecnológica - y culturalmente a una velocidad vertiginosa. Información es un mensaje que hace una diferencia, ya sea como forma o como "oferta de sentido". Esta teoría se presenta como un paradigma postal que lee la tradición greco-latina del concepto de informatio desde la perspectiva comunicacional moderna. Pero también va mas allá de un rechazo de la aplicación del paradigma postal a ámbitos no humanos o de pensar una analogía entre mensajes y mensajeros humanos cuando se observan procesos comunicacionales o 'postálicos' no humanos. ¿Qué nos impide pensar las formas y no sólo las informaciones como mensajes? Les propongo investigar e imaginar modelos y reglas de funcionamiento de las sociedades actuales y futuras, así llamadas de la información y del conocimiento, que están basadas en un intercambio cada vez más complejo de mensajes y en particular de mensajes digitales.

Los límites de mi historia de la noción de información son evidentemente los de la tradición filosófica occidental y de algunas lenguas de dicha tradición, pero el mensaje de esta investigación, es la idea de un paradigma postal que conecte, sin homogenizar las diferencias, fenómenos angeléticos humanos y no humanos. Y esto, naturalmente, sin ambiciones misioneras. En un texto que él considera como su "mejor obra" escribe Ivan Illich:

El libro ha dejado de ser la metáfora de la época; la pantalla lo ha remplazado. El texto alfabético se ha convertido en una más de las múltiples formas de codificar algo, que ahora se denomina "el mensaje.

\footnotetext{
${ }^{69}$ Ver del autor: Ethik im Netz. (2003, p. 105-122). Online: <http://www.capurro.de/botschaft.htm>; Leben im Informationszeitalter (1995, p. 97-109); Angeletics: a Message Theory (2003, p. 58-71), Online: <http://www.capurro.de/angeletics_zkm.html>.

${ }^{70}$ Ivan Illich (2004). Primera edición en inglés (1993).
} 
Tal vez estemos pasando de la edad del libro a través de la edad de la información hacia la edad del mensaje. La edad de la información nos ha puesto a disposición no sólo un nuevo alfabeto sino también nuevas formas de codificar mensajes sirviéndonos en especial de mensajeros digitales. No somos meros lectores del código genético. ${ }^{71} \mathrm{Si}$ lo concebimos como mensaje nos vemos también, pensándonos desde la "edad del libro" (Illich), como escritores. Cuando los textos - los de la naturaleza y los de la cultura- se conciben como mensajes, los escritores y lectores se convierten en mensajeros. Para que esto funcione a nivel social sin estructuras verticales de poder que bloqueen ad libitum dichos procesos, es indispensable que desarrollemos y mantengamos dispositivos de comunicación bidireccionales, horizontales y recursivos. La discusión de la noción de información en el siglo XX nos ha abierto los ojos con respecto al peligro de una concepción unilateral, vertical y no recursiva de la trasmisión de mensajes. El concepto moderno de información opera, en otras palabras, como un correctivo al concepto heteronómico de mensaje. Y viceversa: el concepto de mensaje pone de manifiesto algo que subyace implícita o explícitamente al concepto de información. La percepción crítica de esta tensión entre autonomía y heteronomía, horizontalidad y verticalidad, información y mensaje ha sido posible gracias al sistema de trasmisión de mensajes que llamamos Internet si lo vemos desde la genealogía de la noción de información. La cual desemboca en el espacio de reflexión que llamamos ética de la información.

\section{Referências}

AUSTIN, J.L. Philosophical Papers. URMSON, J.C.; WARNOCK, G.J. (Eds.). Oxford: Clarendon Press, 1961.

BAR-HILLEL, Y. Language and Information. London: Addison-Wesley, 1973.

BAR-HILLEL, Y. \& CARNAP, R. Semantic information. British Journal of Science, v. 4, p. $147-157,1953$.

BARWISE, J.; PERRY, J. Situations and Attitudes. Cambridge: MIT Press, 1983.

BARWISE. J.; SELIGMAN, J. Information Flows: The Logic of Distributed Systems, Cambridge, UK: Cambridge University Press, 1997.

BATESON, G. Steps to an Ecology of Mind. New York: Ballantine Books, 1972.

BENNETT, C.H. \& DIVICENZO, D.P. Quantum information and computation. Nature, v.

\footnotetext{
${ }^{71}$ Ver Hans Blumenberg: Die Lesbarkeit der Welt. (1986).
} 
404, p. 247-255, 2000.

BLUMENBERG, H. Die Lesbarkeit der Welt. Frankfurt am Main: Suhrkamp, 1986.

BOUGNOUX, D. Sciences de l'information et de la communication. Paris: Larousse, 1993.

BRIER, S. (1999). What is a possible ontological and epistemological framework for a true universal "information science?" The suggestion of a cybersemiotics. In: HOFKIRCHNER, W. (Ed.). The Quest for a Unified Theory of Information. Amsterdam: Gordon and Breach, 1999. p. 79-99.

BUCKLAND, M.K. Information and Information systems. New York: Praeger, 1991.

CAPURRO, R. Information. Ein Beitrag zur etymologischen und ideengeschichtlichen Begründung des Informationsbegriffs. München: Saur, 1978.

CAPURRO, R. Leben im Informationszeitalter. Berlin: Akademie Verlag, 1995.

CAPURRO, R. Informationsbegriffe und ihre Bedeutungsnetze. Ethik und

Sozialwissenschaften, v. 1, n. 12, p. 14-17, 2001.

CAPURRO, R. On the Genealogy of Information. In: KORNWACHS, K.; JACOBY, K. (Eds.). Information. New questions to a multidisciplinary concept. Berlin: Akademie Verlag, 2001. p. 259-270.

CAPURRO, R. Angeletics - A Message Theory. In: DIEBNER, Hans H.; RAMSAY, Lehan (Eds.). Hierarchies of Communication. Karlsruhe: Verlag ZKM, 2003. p. 58-71.

CAPURRO, R. Ethik im Netz. Stuttgart: Franz Steiner Verlag, 2003.

CAPURRO, R. Towards an ontological foundation of information ethics. Ethics and Information Technology, v. 8, n. 4, p. 175-186, 2006.

CAPURRO, R. \& HJØRLAND, B. (2003). The Concept of Information. In: CRONIN, Blaise (Ed.). Annual Review of Information Science and Technology (ARIST). Medford: Information Today, 2003. v. 37. p. 343-411.

CAPURRO, R.; FLEISSNER, P.; HOFKIRCHNER, P. Is a Unified Theory of Information Feasible? A Trialogue. In: HOFKIRCHNER, Wolfgang (Ed.). The Quest for a Unified Theory of Information. Amsterdam: Gordon and Breach, 1999. p. 9-30.

CASTELLS, M. The information age: economy, society and culture. Oxford, UK: Blackwell, 1996. 3v.

CERVANTES, M. Don Quijote de la Mancha. Barcelona: Editorial Planeta, 1991.

CORNELLA, A. Infonomia.com. La empresa es información. Bilbao: Deusto, 2000.

DESCARTES, R. Meditationes de prima philosophia. Secundae Responsiones. In: ADAM, C.; TANNERY, P. (Eds.). Oeuvres. Paris: Vrin, 1996. v.7. 
DRETSKE, F. I. Knowledge and the flow of information. Cambridge, MA: MIT Press, 1981.

DRETSKE, F. I. Minds, machines and meaning. In: MITCHAM, C.; HUNING, A. (Eds.). Philosophy and

technology II. Information technology and computers in theory and practice. Dordrecht: Reidel, 1986. p. 97-106.

FLEISSNER, P.; HOFKIRCHNER, W. Informatio revisited. Wider den dinglichen Informationsbegriff. Informatik-Forum, v. 8, p. 126-131, 1995.

FLORIDI, L. (Ed.). The Blackwell Guide to the Philosophy of Information. Oxford, UK: Blackwell, 2004.

FLORIDI, L. Information. The Blackwell Guide to the Philosophy of Information. Oxford, UK: Blackwell, 2004. p. 40-61.

FLORIDI, L. On the Intrinsic Value of Information Objects and the Infosphere. Ethics and Information Technology, v. 4, p. 287-304, 2003.

FLORIDI, L. Information Ethics: On the Theoretical Foundations of Computer Ethics. Ethics and Information Technology 1, p.37-56, 1999.

FOERSTER, H. V. Observing systems. Seaside, CA: Intersystems Publications, 1984.

FURETIERE, A. Dictionnaire universel contenant tous les mots françois tant vieux que modernes, \& les termes de toutes les sciences et des arts. La Haya, Rotterdam: La Veuve van Dole, 1725.

GÜNTHER, G. Das Bewußtsein der Maschinen: Eine Metaphysik der Kybernetik. Krefeld, Baden-Baden: Agis Verlag, 1963.

HARTLEY, R.V.L. Transmission of Information. Bell System Technical Journal, v. 7, p. 335-363, 1928.

HEIDEGGER, M. Sein und Zeit. Tübingen: Niemeyer 1976.

HOFKIRCHNER, Wolfgang (Ed.). The Quest for a Unified Theory of Information. Amsterdam: Gordon and Breach, 1999.

ILLICH, I. (2004). En el viñedo del texto. Etología de la lectura: un comenario al "Didascalion" de Hugo de San Víctor. México: Fondo de Cutura Económica, 2004.

ISRAEL, D.; PERRY, J. What is information? In: HANSON, P. (Ed.). Information, language and cognition. Vancouver, BC: University of British Columbia Press, 1990. p. 119.

JANICH, P. Informationsbegriff und methodisch-kulturalistische Philosophie. Ethik und Sozialwissenschaften, v. 2, p. 169-182, 1998. 
KARPATSCHOF, G. Human activity: contributions to the anthropological sciences from the perspective of activity theory. Copenhagen: Dansk Psykologisk Forlag, 2000.

KORNWACHS, K. (1996). Pragmatic information and system surface. In: KORNWACHS, K.; JACOBY, K. Information. New questions to a multidisciplinary concept. Berlin: Akademie Verlag, 1996. p. 163-185.

LALANDE, A. Vocabulaire technique et critique de la philosophie. Paris: Presses Universitaires de France, 1991.

LUHMANN, N. Soziale Systeme. Frankfurt am Main: Suhrkamp, 1987.

LYRE, H. Quantentheorie der Information. Wien: Springer, 1998.

MACHLUP, F. Semantics quirks in studies of information. In: MACHLUP, Fritz; MANSFIELD, Una. (Eds.). The Study of Information. Interdisciplinary Messages. New York: Wiley, 1983. p. 641-671.

MACHLUP, Fritz; MANSFIELD, Una. (Eds.). The Study of Information. Interdisciplinary Messages. New York: Wiley, 1983. p. 641-671.

MARGEL, S. Le tombeau du dieu artisan. Paris: Éditions du Minuit, 1995.

MARIJUAN, P.C. First conference on foundations of information science. From computers and quantum physics to cells, nervous systems, and societies. Bio Systems, v. 38, p. 87-96, 1996.

MATURANA, H.R.; VARELA, F.J. Autopoiesis and cognition. Dordrecht: Reidel, 1980.

NONAKA, I. \& TAKEUCHI, H. The knowledge-creating company. New York: Oxford University Press, 1995.

OESER, E. Wissenschaft und Information. Wien: Oldenbourg, 1976.

PÉREZ GUTIÉRREZ, M. El fenómeno de la información. Una aproximación conceptual al flujo informativo. Madrid: Trotta, 2000.

PETERS, J.D. Information: Notes toward a critical history. Journal of Communication Inquiry, v. 12, p. 10-24, 1988.

QVORTRUP, L. The controversy over the concept of information. An overview and a selected and annotated bibliography. Cybernetics \& Human Knowing, v. 1, n. 4, p. 3-24, 1993.

RITTER, J. et al. (Eds.). Historisches Wörterbuch der Philosophie. Darmstadt: Wissenschaftliche Buchgesellschaft, 1971.

SCHNELLE, H. Information. In: RITTER, J. (Ed.). Historisches Wörterbuch der Philosophie, IV. Stuttgart: Schwabe, 1976, p. 116-117. 
SHANNON, C. E. A Mathematical Theory of Communication. Bell System Technical Journal, v. 27, 1948. p. 379-423.

SHANNON, C. E.; WEAVER, W. The mathematical theory of communication. Urbana: University of Illinois Press, 1972.

STONIER, T. Information and the internal structure of the universe: an exploration into information physics. London: Springer, 1990.

STONIER, T. Information and meaning: an evolutionary perspective. London: Springer, 1997.

STONIER, T. Information as a basic property of the universe. Bio Systems, v. 38, p. 135-140, 1996.

TOMAS DE AQUINO. Summa Theologicae. Roma: Forzanti, 1923.

URSUL, A.D. Information: eine philosophische Studie. Berlin: Dietz, 1970.

VÖLZ, H. Information I: studie zur Vielfalt und Einheit der Information. Berlin: Akademie Verlag, 1982.

VÖLZ, H. Information II: Ergänzungsband zur Vielfalt und Einheit der Information -

Theorie und Anwendung vor allem in der Biologie, Medizin und Semiotik. Berlin: Akademie Verlag, 1983.

WEBSTER, F. Theories of the information society. London: Routledge, 1995.

WEIZSÄCKER, C. F. VON. Information und Imagination. In: BAYERISCHE AKADEMIE DER SCHÖNEN KÜNSTE (Ed.). Information und Imagination. München: Piper, 1973.

WEIZSÄCKER, C. F. VON. Die Einheit der Natur. München: DTV, 1974.

WEIZSÄCKER, C. F. VON. Aufbau der Physik. München: Hanser, 1985.

WEIZSÄCKER, C. F. VON. Zeit und Wissen. München: Hanser, 1992.

WIENER, N. (1961). Cybernetics or control and communication in the animal and the machine. New York: MIT Press, 1961.

WITTGENSTEIN, L. Philosophische Untersuchungen. Frankfurt am Main: Suhrkamp, 1984.

Anexo

REAL ACADEMIA ESPAÑOLA. Diccionario de la Lengua castellana, llamado de Autoridades. Madrid: s. n., 1734. Tomo I. p. 267-268. 
INFORMACION, s.f. El acto de informarse ò informar de algo. Lat. Informatio. FUENM. S. Pio V.f.118. Por siniestras informaciónes desacreditados.

INFORMACIÓN. Se llaman en lo forense las diligencias jurídicas que se hacen de cualquier hecho ù delito, para averiguarle, y certificarse de su verdad. Lat. Inquisitio. CERV. Quix. Tom.I.cap.41. Hecha su información de quanto le convenia, se fué à la Ciudad de Granáda. QUEV. Mus.7.Rom.Satyr. que empieza, pues me haceis casamentero.

Al caminante en los pueblos se le pide información, Temiendole mas que à peste.

INFORMACIÓN. Se llama en la Philosophía la introducción de la forma en la matéria, para formar el compuesto. Lat. Informatio.

INFORMACIÓNES. En plural, se llaman las diligencias secretas, que se hacen de la calidad y nobleza de alguno, en orden à conferirle algun oficio, dignidad ò insignia. Lat. Secretae inquisitiones. ESTABLEC. DE SANT. Tit. 2. cap. 14. Mandámos, que despues de vistas en el Consejo las informaciónes, que se hacen para Hábitos de Caballeros, se tornen à cerrar y sellar.

INFORMACIÓN EN DERECHO. La alegación escrita, que el Abogado hace para instruir à los Jueces de la justicia de alguna de las partes, en los pleitos y causas civiles o crimináles. CALD. Aut. La immunidad del sagrado.

Yo he de llenarlàs, cumpliendo de esse volumen lo que à la esperanza falta, con la nueva información, que en derecho en favor haga.

INFORMANTE. S.m. El que lleva la comissión y el cargo de hacer las informaciónes de calidad y nobleza, ò limpieza. Lat. Inquisitor secretus. RECOP. Lib. 1.tit.7,1. 35. En tal caso se podrán examinar los testigos que en él se citan, como pudiera el informante examinarlos por sí mismo.

INFORMAR. V.a. Term. Philosóphico. Dar la forma à la materia, ò unirse con ella. Lat. Informare, que es de donde viene. CALD. Aut. A Dios por razon de estado. En embrion el alma, aun no informa órganos al cuerpo.

INFORMAR. Vale tambien dar noticias à alguno ò ponerle en el hecho de alguna cosa. Lat. Informare. Certiorem facere. CERV. Quix. Tom1,cap.22. Pidió à los que iban en su guarda fuessen servidos de informarle, y decirle la cáusa, ò causas por que llevaban aquella gente. SAAV. Empr. 66. La peregrinacion es gran maestra de la prudencia, quando se emprende para informar, no para deleitar solamente el ánimo.

INFORMAR. Significa tambien decir, ò poner en el hecho y derecho de alguna causa al Juez, el Abogado de ella para que sentencie. Lat. Certiorem facere. Informare. CALD. Aut. La immunidad del sagrado. 
No me acobarda la competéncia; en derecho sabré informar.

INFORMARSE. Vale tambien tomar noticias ò inquirir alguna cosa. Lat. Inquirere. Grac. Xenoph.lib.4.f.37. Yo me informaré como y quando, y en qué tiempo los hirieron, y daré mi parecer sobre ello. MEND. Vid. De

N. Señora, Copl.112.

Infórmase, y no resiste al soberano decreto, que no en todas ocasiones quiere Dios sentidos ciegos.

INFORMADO, DA. part.pass. del verbo informar en sus acepciones. Lat. Informatus. Inquisitus. MARIAN. Hist.Esp.lib.7.cap.2. Los Moros informados de lo que pretendía Don Pelayo, por la huella, fueron en su busca.

INFORME. s.m. El mismo hecho de informar, ù dar noticia de alguna cosa. Lat. informatio. CRUZAD. Cort.Sant.tom.3. Pass.del odio, fest.4. Aunque no tengan mas fundamento, que un mal informe y una mentira.

INFORME. En lo forense significa la oración que hace el abogado, en hecho y derecho de la causa que defiende. Lat. Informatio. 